\title{
Communication \\ Alkene Epoxidations Mediated by Mn-Salen Macrocyclic Catalysts
}

\author{
Andrea Pappalardo ${ }^{1,2}$, Francesco P. Ballistreri ${ }^{1}$, Rosa Maria Toscano ${ }^{1}$, Maria Assunta Chiacchio ${ }^{3}$, Laura Legnani ${ }^{3}$, \\ Giovanni Grazioso ${ }^{4}$ (D) Lucia Veltri ${ }^{5}$ and Giuseppe Trusso Sfrazzetto ${ }^{1,2, *(D)}$
}

1 Department of Chemical Sciences, University of Catania, 95125 Catania, Italy; andrea.pappalardo@unict.it (A.P.); fbalistreri@unict.it (F.P.B.); rmtoscano@unict.it (R.M.T.)

2 Research Unit of Catania, National Interuniversity Consortium for Materials Science and Technology (I.N.S.T.M.), 95125 Catania, Italy

3 Department of Drug Sciences, University of Catania, Viale A. Doria 6, 95125 Catania, Italy; ma.chiacchio@unict.it (M.A.C.); laura.legnani@unipv.it (L.L.)

4 Dipartimento di Scienze Farmaceutiche, Università degli Studi di Milano, Via L. Mangiagalli 25, 20133 Milan, Italy; giovanni.grazioso@unimi.it

5 Laboratory of Industrial and Synthetic Organic Chemistry (LISOC), Department of Chemistry and Chemical Technologies, University of Calabria, Via P. Bucci 12/C, 87036 Arcavacata di Rende, Italy; lucia.veltri@unical.it

* Correspondence: giuseppe.trusso@unict.it; Tel.: +39-095-7385201

check for updates

Citation: Pappalardo, A.; Ballistreri, F.P.; Toscano, R.M.; Chiacchio, M.A.; Legnani, L.; Grazioso, G.; Veltri, L.; Trusso Sfrazzetto, G. Alkene Epoxidations Mediated by Mn-Salen Macrocyclic Catalysts. Catalysts 2021, 11, 465. https://doi.org/10.3390/ catal11040465

Academic Editor:

Jean-Marc Campagne

Received: 17 March 2021

Accepted: 31 March 2021

Published: 2 April 2021

Publisher's Note: MDPI stays neutral with regard to jurisdictional claims in published maps and institutional affiliations.

Copyright: (c) 2021 by the authors. Licensee MDPI, Basel, Switzerland. This article is an open access article distributed under the terms and conditions of the Creative Commons Attribution (CC BY) license (https:/ / creativecommons.org/licenses/by/ $4.0 /)$.

\begin{abstract}
Three new chiral Mn macrocycle catalysts containing 20 or 40 atoms in the macrocycle were synthetized and tested in the enantioselective epoxidation of cis- $\beta$-ethyl-styrene and $1,2-$ dihydronathalene. The effect of the presence of a binaphtol (BINOL) compound in the catalyst backbone has been evaluated, including by Density Functional Theory (DFT) calculations.
\end{abstract}

Keywords: enantioselective; epoxidation; Mn catalyst; alkene; DFT

\section{Introduction}

Asymmetric epoxidation of unfunctionalized prochiral olefins catalyzed by chiral (salen)Mn(III) complexes has proven to be one of the most useful reactions in organic synthesis since it generates chiral epoxides containing two new stereocenters, which can be easily transformed into a large variety of compounds useful in industrial, biological, pharmaceutical and agricultural fields [1]. The origins of high enantioselectivity in this reaction have been extensively studied [2] but, until now, not fully elucidated. A possible electronic effect of the 5,5'-substituents in the salen ligand is invoked $[3,4]$, but the most common explanation is attributed to the directions of approach of the alkene to the manganese active site (manganese-oxo) [5]. The side-on approach where the double bond of the alkene is parallel to the salen ligand is generally accepted, but four main directions to the Mn-oxo [6,7] moiety have been proposed in the literature (Figure 1).

Katsuki et al. hypothesized that the substrate approaches the catalyst along the Mn-N bond (Figure 1, path A) [8-10]. In addition, Jacobsen assumed that (salen) $\mathrm{Mn}=\mathrm{O}$ has a planar conformation and steric bulk at the 3,3'- and 5,5'-positions, thus forcing the substrate to approach over the ethylenediamine backbone (Figure 1, path B) [11-15]. Furthermore, Katsuki also proposed an approach direction by pathway C, along the $5,5^{\prime}$-position $[16,17]$. It is generally accepted that the increase of steric bulkiness in the 3,3'-positions of the salen ligand enhances enantioselectivity, suggesting that the alkene does not approach from this direction to the metal center (Figure 1, path D) [18-26].

More recently, a new justification about the origin of enantioselectivity was proposed by Corey et al. $[14,15]$. They asserted that none of these explanations seem to be plausible when the mechanism is represented in three dimensions. They proposed that the pretransition state geometry could be stabilized by electrostatic interaction between a partial positive charge localized in the benzylic carbon atom of alkene and the partial negative 
charge of phenoxy oxygen of the catalyst (Figure 2a). In this hypothesis, the transition state assembly is slightly similar to a [3+2] cycloaddition.

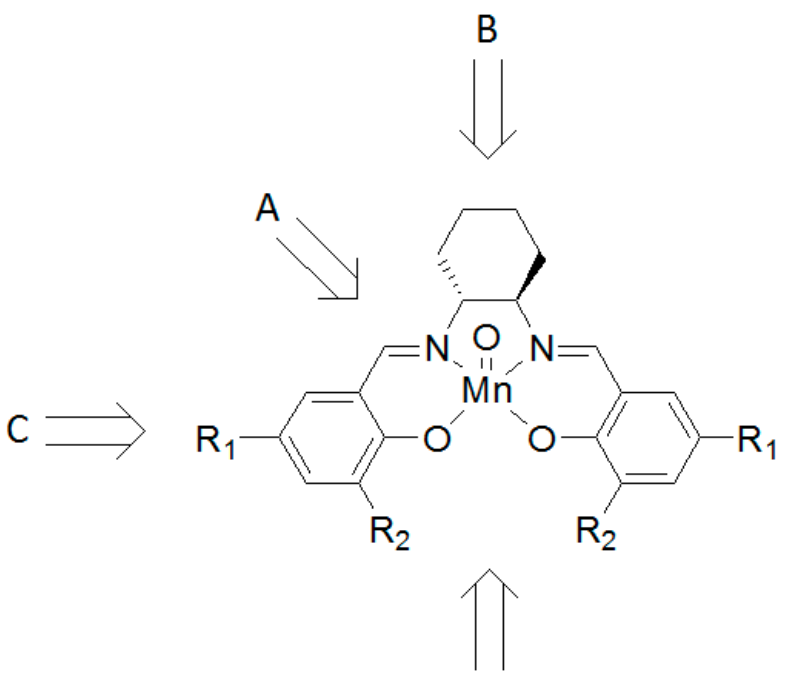

D

Figure 1. Proposed directions of approach to the active Mn-oxo moiety of (salen)Mn.

a)

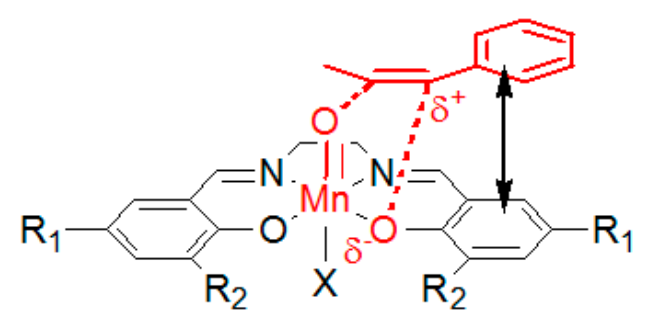

b)

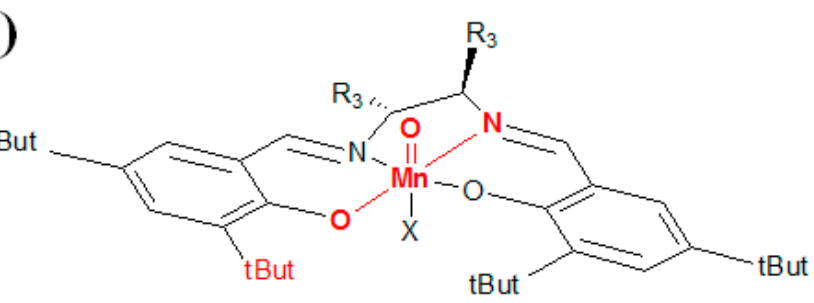

Figure 2. (a) Pre-transition state geometry invoked by Corey; (b) spatial arrangement of the salen catalyst.

A geometric consequence of the canted arrangement of the salen rings due to the configuration of the chiral diimine bridge is that the neighboring t-butyl groups in the ortho position to the coordinated phenolic oxygens occupy spaces on opposite faces of the $\mathrm{N}$ $\mathrm{Mn}-\mathrm{O}$ plane (Figure $2 \mathrm{~b}$ ). Considering Corey's hypothesis, the orientation of substrates, in particular of aromatic conjugate alkenes, in the (salen)Mn-oxo complex avoids unfavorable steric repulsion with the $t$-butyl groups, taking advantage of stabilizing $\pi$-stacking of the aromatic ring of the alkene and the aryloxy group of the catalyst (Figure 2a).

\section{Results and Discussion}

To better understand the importance of the approach direction as well as the importance of bulkiness in the 3,3'-positions, we report here three new chiral Mn macrocycle catalysts based on the classic Jacobsen's salen catalyst bearing an $(R)-(+)$-BINOL unit in the 3,3'-position of the salen backbone (see Chart 1 ). These catalysts differ in the size of 
the macrocycle, having 20 members (in the case of Mn-M20) or 40 members (in the case of $\mathrm{Mn}-\mathrm{M} 40-\mathrm{DiPh}$ and Mn-M40-Cycl) in the macrocycle. In addition, their activity towards epoxidation by using two alkene models (cis- $\beta$-methyl-styrene and 1,2-dihydronaphtalene) was evaluated.

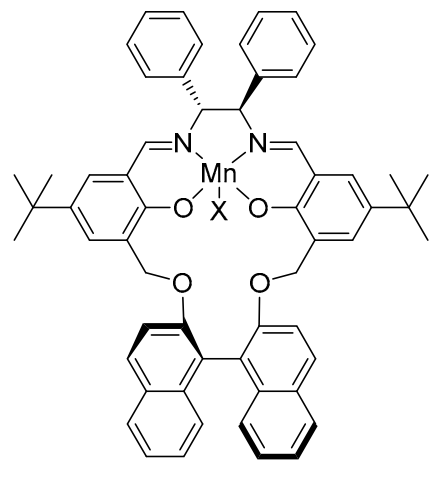

Mn-M20

$\left(\mathrm{X}=\mathrm{CH}_{3} \mathrm{COO}^{-}\right)$

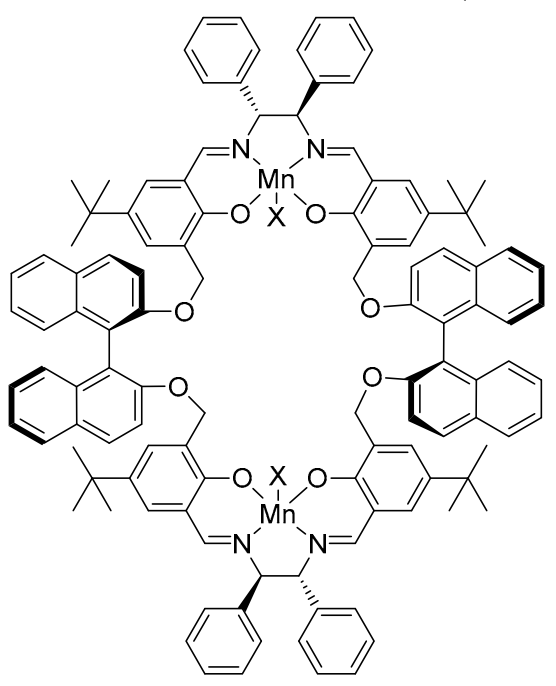

Mn-M40-DiPh

$\left(\mathrm{X}=\mathrm{CH}_{3} \mathrm{COO}^{-}\right)$

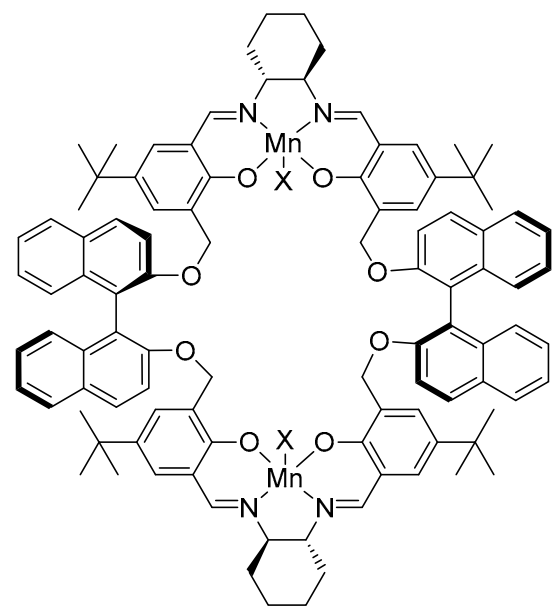

Mn-M40-Cycl

$\left(\mathrm{X}=\mathrm{CH}_{3} \mathrm{COO}^{-}\right)$

Chart 1. Chemical structures of Mn macrocycle catalysts.

Mn catalysts reported in Chart 1 were obtained starting from the corresponding macrocycle ligands (M20 and M40) [16,17] by complexation with manganese(III) acetate in ethanol [18]. Compounds were collected by filtration and characterized by ESI-MS (Electrospry Ionization-Mass Spectrometry) measurements. The chiral diimine bridge of Mn-M20 and Mn-M40-DiPh is (1R,2R)-diphenyl-ethyl group, while Mn-M40-Cycl leads a (1R-trans)-cyclohexyl group.

Table 1 shows epoxidation results in terms of conversions, epoxide yields and enantiomeric excess (EE). The results clearly show a different epoxidation rate based on the nature of the alkene: reactions with 1,2-dihydronathalene (Table 1, entries 7-12) are faster than reactions with cis- $\beta$-methyl-styrene (Table 1, entries 1-6) [19-21]. Moreover, the presence of PPNO (4-phenyl-pyridine $\mathrm{N}$-oxide) as a coligand increases reaction rates, conversions and enantiomeric excesses, suggesting a favorable electronic effect to the manganese metal center [22]. 
Table 1. Enantioselective epoxidation of alkenes with $\mathrm{NaClO}$ catalyzed by $\mathrm{Mn}$ macrocycle catalysts ${ }^{\mathrm{a}}$.

\begin{tabular}{|c|c|c|c|c|c|c|}
\hline Alkene & Entry & Catalyst & Time (min) & Conv. ${ }^{b}(\%)$ & Yield $^{b}(\%)$ & $\mathrm{EE}^{\mathrm{b}}(\%)$ \\
\hline \multirow{6}{*}{ 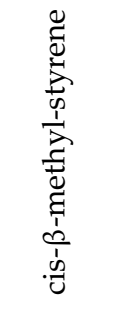 } & $1^{\mathrm{c}}$ & Mn-M20 & 300 & 80 & 88 & 16 \\
\hline & 2 & Mn-M20 & 240 & 90 & 88 & 27 \\
\hline & $3^{c}$ & Mn-M40-DiPh & 420 & 78 & 84 & 17 \\
\hline & 4 & Mn-M40-DiPh & 300 & 87 & 82 & 31 \\
\hline & $5^{c}$ & Mn-M40-Cycl & 420 & 77 & 85 & 12 \\
\hline & 6 & Mn-M40-Cycl & 300 & 89 & 84 & 30 \\
\hline \multirow{6}{*}{ 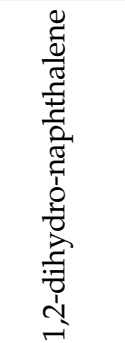 } & $7^{c}$ & Mn-M20 & 60 & 92 & 93 & 23 \\
\hline & 8 & Mn-M20 & 30 & 95 & 94 & 38 \\
\hline & $9^{c}$ & Mn-M40-DiPh & 90 & 90 & 91 & 25 \\
\hline & 10 & Mn-M40-DiPh & 30 & 88 & 89 & 35 \\
\hline & $11^{\mathrm{c}}$ & Mn-M40-Cycl & 90 & 80 & 93 & 29 \\
\hline & 12 & Mn-M40-Cycl & 30 & 90 & 99 & 36 \\
\hline
\end{tabular}

${ }^{\mathrm{a}}$ In all the experiments, alkene $=0.14 \mathrm{M}$, catalyst $=0.007 \mathrm{M}$, coligand $=4-\mathrm{PPNO}=0.07 \mathrm{M}, \mathrm{NaClO}=0.14 \mathrm{M} \mathrm{Na}_{2} \mathrm{HPO}_{4}=0.05 \mathrm{M}$, buffered at $\mathrm{pH}=11$.2. In all the cases, configuration of epoxides is determined by measuring the optical rotation. ${ }^{\mathrm{b}}$ Determined by GC on chiral columns. ${ }^{\mathrm{c}}$ No coligand added.

Although these macrocycle catalysts possess different chiral diimine bridges (diphenyl or cyclohexyl) and, consequently, different steric hindrances to the Mn-oxo group along approach directions A and B (reported in Figure 1), the enantiomeric excess values were similar. These data suggest that steric restrictions closer to the active catalyst site do not play a primary role in the determination of the enantioselectivity values. Furthermore, the different size of the macrocycles and the different steric hindrance along pathway $\mathrm{D}$ represented in Figure 1 did not lead to different EE values. The lower EE values obtained with these macrocycles with respect to other Mn-salen catalysts should have been due to the presence of the chiral $(R)-(+)-B I N O L$ compound that can reduce the efficiency of the enantioselective oxygen transfer.

\section{Theoretical Calculations}

In order to rationalize the enantiomeric excess results, DFT studies were performed on the simplest catalyst. First, our attention was focused on Mn-M20 that was optimized and the obtained 3D plots together with the corresponding activated forms containing the $\mathrm{Mn}=\mathrm{O}$ species formed in the presence of $\mathrm{NaClO}$ are reported in Figure 3.

The catalyst and its activated form showed overlapping structures characterized by the steric hindrances of BINOL groups.

In order to rationalize the enantioselectivity of the reaction, the two transition states leading to the two possible enantiomeric epoxides were located by using DFT calculations [23-26]. The computational study was carried out on the epoxidation reaction involving Mn-M20 in its activated form as a catalyst and cis- $\beta$-methyl-styrene, which seems to be a good compromise between the size of the system and the accuracy of the calculation.

The located transition state (TS) present the expected imaginary frequencies on the $\mathrm{O}$ transfer (see Supporting Information). In Figure 4, the formation bond distances are shown. The favored $(2 S, 3 R)$-TS (Figure $4 \mathrm{~A})$ had the bond less formed $(1.77 \AA)$ than the $(2 R, 3 S)$-TS (Figure 4B) (1.74 $)$. 


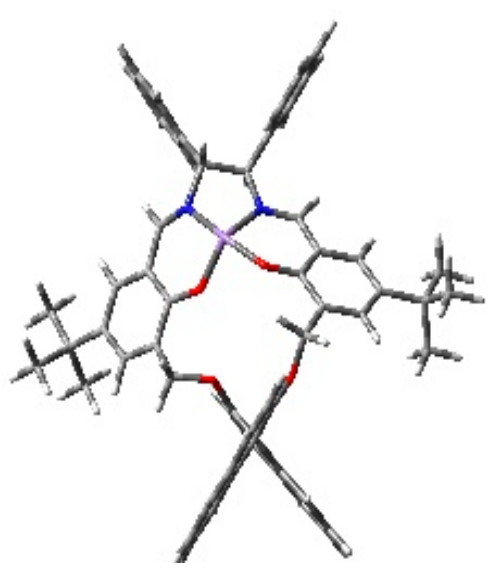

(A)

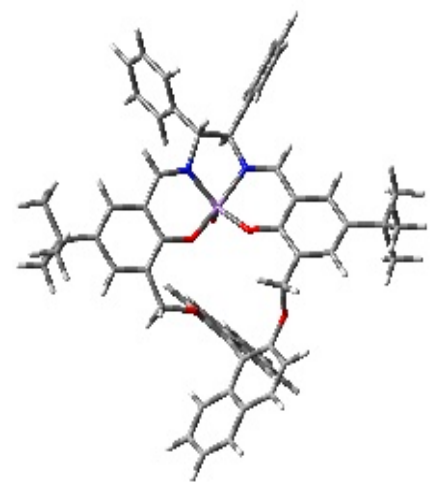

(B)

Figure 3. 3D-plots of Mn-M20 (A) and the corresponding activated structure (B) minimized at the b3lyp/def2svp level for Mn and b3lyp/6-31 g(d) for all other atoms.

A

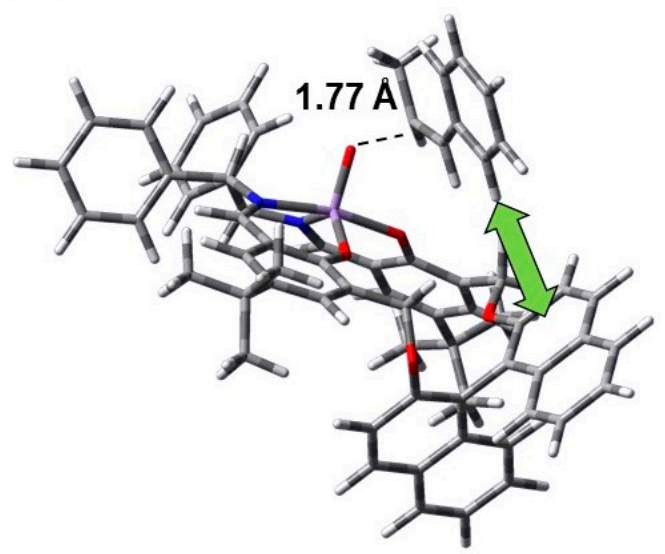

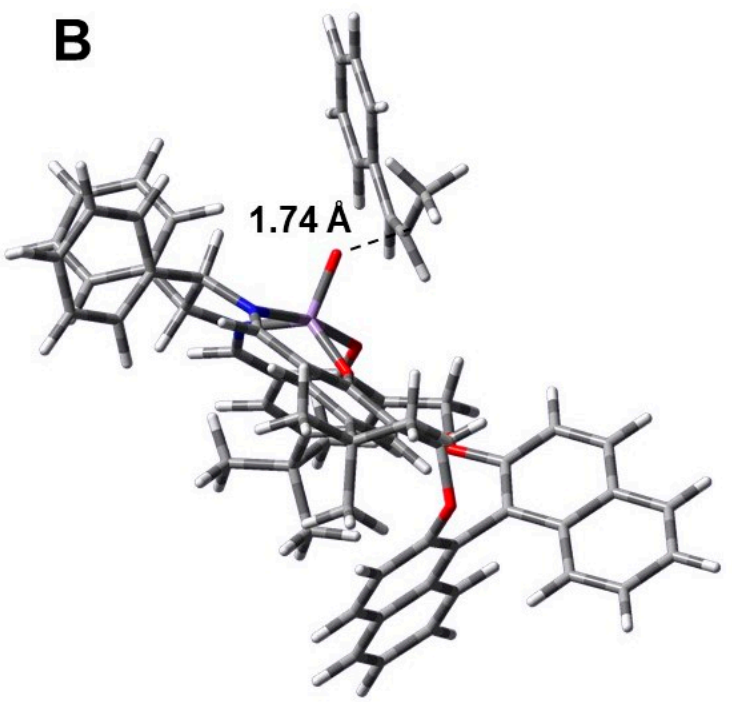

Figure 4. Three-dimensional plots of the two enantiomeric transition states for the epoxidation of cis- $\beta$-methyl-styrene with Mn-M20 leading to the $(2 S, 3 R)(\mathbf{A})$ and the $(2 R, 3 S)(\mathbf{B})$ epoxides, respectively. The green arrow highlights the $\mathrm{CH}-\pi$ interaction between the alkene and the aromatic ring of the BINOL compound. 
Calculations supported the enantiomeric excess experimental results. The calculated activation energies were comparable in the two cases with values of about 7 and $8 \mathrm{kcal} / \mathrm{mol}$ in vacuo for the transition states leading to the $(2 S, 3 R)$ epoxide and the $(2 R, 3 S)$ epoxide, respectively (Figure 4). Considering the free energy values, the reaction was slower due to energy barriers of about 21 and $22 \mathrm{kcal} / \mathrm{mol}$ for the transition states leading to the $(2 S, 3 R)$ epoxide and the $(2 R, 3 S)$ epoxide, respectively. Thus, the transition state related to the $(2 S, 3 R)$ epoxide was favored $(1.18 \mathrm{kcal} / \mathrm{mol})$, probably due to the $\pi-\pi$ stacking interactions between the aromatic ring of the alkene and the salicylaldehyde ring of the catalyst, as well as the $\mathrm{CH}-\pi$ interaction with the BINOL compound (showed by green arrows in Figure $4 \mathrm{~A}$ ). If the alkene attacks the $\mathrm{Mn}=\mathrm{O}$ with the opposite face (Figure $4 \mathrm{~B}$ ) leading to the $(2 R, 3 S)$ epoxide, these interactions cannot be found.

The ratio between the two enantiomers on the basis of the transition state energies was 78:22 with a theoretical enantiomeric excess of $56 \%$ in vacuo. Considering methanol as a solvent, the energy barriers resulted in 10.62 and $11.02 \mathrm{kcal} / \mathrm{mol}$ for the transition states related to the $(2 S, 3 R)$ and $(2 R, 3 S)$ epoxides, respectively, with a ratio between the two enantiomers of $66: 34$ and a theoretical EE value of $32 \%$, which was in line with the experimental one (Table 1, entry 2).

Taking into account these results and considerations, substituents in the 3,3'-positions play a crucial role in the determination of the enantioselectivity values. Their fundamental importance is probably ascribed to the stabilizing/destabilizing effect of the transition state, as showed in Figures 2a and 4A.

\section{Materials and Methods}

GC analyses of the epoxidation reaction were performed with a GC-FID (Flame Ionization Detector) instrument. The EE values were estimated and calculated by using a proper chiral column DMePeBETACDX $(25 \mathrm{~m} \times 0.25 \mathrm{~mm}$ ID $\times 0.25 \mu \mathrm{m}$ film $)$ for 1,2dihydronaphthalene (isotherm $\left.150{ }^{\circ} \mathrm{C}\right)$ and DMeTButiSililBETA $(25 \mathrm{~m} \times 0.25 \mathrm{~mm}$ ID $\times 0.25 \mu \mathrm{m}$ film) for cis- $\beta$-methyl-styrene (column conditions: $50{ }^{\circ} \mathrm{C}(0 \mathrm{~min})$ to $120{ }^{\circ} \mathrm{C}$ $(1 \mathrm{~min})$ at $2{ }^{\circ} \mathrm{C} / \mathrm{min}$ ). The injector and detector temperatures were maintained at $250^{\circ} \mathrm{C}$ for both columns. As an internal standard, $n$-decane was used throughout. ESI mass spectra were obtained by employing an ES-MS equipped with an ion trap analyzer. The absolute configurations of (1R,2S)-1,2-epoxy-1,2,3,4-tetrahydronaphthalene and of (1R,2S)1,2-epoxy-1-phenylpropane were determined by measuring the optical rotations with a polarimeter. Commercial reagents were used as received without further purification. All the calculations were performed using the Gaussian 16 program package [27]. Optimizations were done in the gas phase at the b3lyp/6-31g(d) level $[28,29]$ for all atoms, while the b3lyp/def2svp was used for Mn to correctly describe the electronic properties of the systems. The solvent effects $\left(\mathrm{CH}_{3} \mathrm{OH}\right)$ were considered by single-point calculations at the same level as above using the self-consistent reaction field (SCRF) method based on the polarizable continuum solvent model (PCM) [30-32]. Vibrational frequencies were computed at the same level of theory to verify that the optimized structures were minimal. Thermodynamics at $298.15 \mathrm{~K}$ allowed the Gibbs free energies to be calculated.

\subsection{Synthesis of Mn Macrocycle Catalysts}

The absolute ethanol solution of the given macrocycle salen-ligand was stirred overnight at room temperature with 1.5 equivalents of manganese(III) acetate in the case of M20 or with three equivalents of manganese(III) acetate in the case of M40. When the starting ligand was completely converted (checked by thin layer chromatography TLC analysis), the solvent was removed under reduced pressure. Then, $5 \mathrm{~mL} \mathrm{CH}_{2} \mathrm{Cl}_{2}$ was added to the remaining crude solid to dissolve the $\mathrm{Mn}$ complex. The residual precipitate (not reacted manganese (III) acetate) was removed and the $\mathrm{CH}_{2} \mathrm{Cl}_{2}$ solution was concentrated in vacuo thus giving the corresponding catalyst with nearly quantitative yield. 
Mn-M20: ESI-MS: detected $m / z, 895[\mathrm{M}]^{+}$(expected, 895.3); analytically calculated values for $\mathrm{C}_{58} \mathrm{H}_{52} \mathrm{MnN}_{2} \mathrm{O}_{4}$ : C, 77.75; $\mathrm{H}, 5.85 ; \mathrm{Mn}, 6.13 ; \mathrm{N}, 3.13 ; \mathrm{O}, 7.14$; values as measured: C, 77.71; Mn, 6.09; N, 3.10; O, 7.11.

Mn-M40-DiPh: ESI-MS: detected $m / z, 895$ [M] ${ }^{2+}$ (expected, 895.8); analytically calculated values for $\mathrm{C}_{116} \mathrm{H}_{104} \mathrm{Mn}_{2} \mathrm{~N}_{4} \mathrm{O}_{8}$ : $\mathrm{C}$, 77.75; $\mathrm{H}, 5.85 ; \mathrm{Mn}, 6.13 ; \mathrm{N}, 3.13 ; \mathrm{O}, 7.14$; values as measured: C, 77.68; Mn, 6.07; N, 3.12; O, 7.10.

Mn-M40-Cycl: ESI-MS: detected $m / z, 797[\mathrm{M}]^{2+}$ (expected, 797.8); analytically calculated values for $\mathrm{C}_{100} \mathrm{H}_{100} \mathrm{Mn}_{2} \mathrm{~N}_{4} \mathrm{O}_{8}$ : $\mathrm{C}, 75.27 ; \mathrm{H}, 6.32 ; \mathrm{Mn}, 6.89 ; \mathrm{N}, 3.51 ; \mathrm{O}, 8.02$; values as measured: C, 75.17; Mn, 6.82; N, 3.48; O, 7.98 .

\subsection{General Procedure for Epoxidation Reactions}

A dichloromethane solution of the substrate $(0.35 \mathrm{mmol})$, chiral macrocycle catalyst (5\%) and 4-phenylpyridine N-oxide (4-PPNO, 50\%), buffered at $\mathrm{pH} 11.2$ with a phosphate buffer, was stirred at $25{ }^{\circ} \mathrm{C}$ with bleach. The reaction was monitored using GC analysis by using $n$-decane as an internal quantitative standard. When the starting material was consumed, the organic phase was removed, dried with $\mathrm{Na}_{2} \mathrm{SO}_{4}$ and purified by preparative layer chromatograpy (PLC) $\left(\mathrm{SiO}_{2}\right.$, cyclohexane/EtOAc $(15: 1, v / v)$. Absolute configurations were compared with literature data $[33,34]$.

\subsection{Computational Methods}

Optimizations were done in the gas phase at the b3lyp/6-31g(d) level [28,29] for all atoms, while the b3lyp/def2svp was used for Mn to correctly describe the electronic properties of the systems. The solvent effects $\left(\mathrm{CH}_{3} \mathrm{OH}\right)$ were considered by single-point calculations at the same level as above using the self-consistent reaction field (SCRF) method based on the polarizable continuum solvent model (PCM) [30-32]. Vibrational frequencies were computed at the same level of theory to verify that the optimized structures were minimal. Thermodynamics at $298.15 \mathrm{~K}$ allowed the Gibbs free energies to be calculated. The $\Delta \mathrm{E}$ values and the percentages of the TS were calculated applying the Boltzmann equation. Using the obtained percentages, the EE values were calculated using the following equation: $\mathrm{EE} \%=[\%$ major compound $-\%$ minor compound $] /[\%$ major compound $+\%$ minor compound] $\times 100$.

\section{Conclusions}

Three new chiral Mn macrocycle catalysts containing 20 or 40 atoms in the macrocycle were synthetized and tested in the enantioselective epoxidation of cis- $\beta$-ethyl-styrene and 1,2-dihydronathalene. Reaction rates depend on the nature of the alkene and the presence of a coligand (PPNO) increases reaction rates, conversions and enantiomeric excesses. Despite the presence of a BINOL compound in the $3,3^{\prime}$ position of the catalyst scaffolds, the enantioselectivities observed were, in general, low, probably due to the distance of these substituent with respect to the metal center. DFT calculations support this hypothesis. In particular, the calculated activation energies of the transition states related to the formation of the enantiomeric epoxides confirm the enantiomeric excesses obtained by experimental measurements.

Supplementary Materials: The following are available online at https:/ /www.mdpi.com/article/10 .3390/catal11040465/s1.

Author Contributions: Conceptualization, F.P.B. and G.T.S.; syntheses and epoxidation reactions, A.P. and R.M.T.; writing-original draft preparation, G.T.S.; conceived, designed, and supervised the computational study, M.A.C. and L.L.; performed the computational simulations and analyzed the in silico data, G.G. and L.V. All authors have read and agreed to the published version of the manuscript.

Funding: The authors thank the University of Catania for the financial support.

Conflicts of Interest: The authors declare no conflict of interest. 


\section{References}

1. Mc Garrigle, E.M.; Gilheany, D.G. Chromium- and Manganese-salen Promoted Epoxidation of Alkenes. Chem. Rev. 2005, 105, 1563-1602. [CrossRef] [PubMed]

2. Jacobsen, E.N.; Zhang, W.; Guler, M.L. Electronic tuning of asymmetric catalysts. J. Am. Chem. Soc. 1991, 113, 6703-6704. [CrossRef]

3. Katsuki, T. Catalytic asymmetric oxidations using optically active (salen) manganese(III) complexes as catalysts. Coord. Chem. Rev. 1995, 140, 189-214. [CrossRef]

4. Houk, K.N.; De Mello, N.C.; Condroski, K.; Fennen, J.; Kasuga, T. Origins of enantioselection in Jacobsen epoxidations. In Proceedings of the Electronic Conference on Heterocyclic Chemistry (ECHET96), London, UK, 24 June-22 July 1996.

5. La Paglia Fragola, V.; Lupo, F.; Pappalardo, A.; Trusso Sfrazzetto, G.; Toscano, R.M.; Ballistreri, F.P.; Tomaselli, G.A.; Gulino, A. A surface-confined $\mathrm{O}=\mathrm{Mn}^{\mathrm{V}}$ (salen) oxene catalyst and high turnover values in asymmetric epoxidation of unfunctionalized olefins. J. Mat. Chem. 2012, 22, 20561. [CrossRef]

6. Hosoya, N.; Hatayama, A.; Yanai, K.; Fujii, H.; Irie, R.; Katsuki, T. Asymmetric epoxidation with optically active (salen) manganese(III) complexes: From which direction does the olefin approach the metal- oxo bond? Synlett 1993, 9, 641-645. [CrossRef]

7. Hamada, T.; Irie, R.; Katsuki, T. How does chiral oxo(salen) manganese(V) complex discriminate the enantioface of simple olefins? Scope and limitation of salen- catalyzed epoxidation. Synlett 1994, 7, 479-481. [CrossRef]

8. Jacobsen, E.N.; Zhang, W.; Muci, A.R.; Ecker, J.R.; Deng, L. Highly enantioselective epoxidation catalysts derived from 1, 2diaminocyclohexane. J. Am. Chem. Soc. 1991, 113, 7063-7064. [CrossRef]

9. Pospisil, P.J.; Carsten, D.H.; Jacobsen, E.N. X- ray structural studies of highly enantioselective Mn(salen) epoxidation catalysts. Chem. A Eur. J. 1996, 2, 974-980. [CrossRef]

10. Hashihayata, T.; Punniyamurthy, T.; Irie, R.; Katsuki, T.; Akita, M.; Moro-oka, Y. Conformational analysis of cationic (R, S)- and $(\mathrm{R}, \mathrm{R})$-(salen) manganese complexes possessing axial chirality as a chiral element based on x-ray crystallography: An explanation of the effect of apical ligand on enantioselection by (salen) manganese catalyst. Tetrahedron 1999, 55, 14599-14610.

11. Katsuki, T. Chiral metallosalen complexes: Structures and catalyst tuning for asymmetric epoxidation and cyclopropanation. Adv. Synth. Catal. 2002, 344, 131-147. [CrossRef]

12. Zhang, W.; Loebach, J.L.; Wilson, S.R.; Jacobsen, E.N. Enantioselective epoxidation of unfunctionalized olefins catalyzed by salen manganese complexes. J. Am. Chem. Soc. 1990, 112, 2801-2803. [CrossRef]

13. Jacobsen, H.; Cavallo, L. A possible mechanism for enantioselectivity in the chiral epoxidation of olefins with [Mn(salen)] catalysts. Chem. A Eur. J. 2001, 7, 800-807. [CrossRef]

14. Kurti, L.; Blewett, M.M.; Corey, E.J. Origin of Enantioselectivity in the Jacobsen Epoxidation of Olefins. Org. Lett. 2009, 11, 4592-4595. [CrossRef]

15. Brown, M.K.; Blewett, M.M.; Colombe, J.R.; Corey, E.J. Mechanism of the Enantioselective Oxidation of Racemic Secondary Alcohols Catalyzed by Chiral Mn(III)-Salen Complexes. J. Am. Chem. Soc. 2010, 132, 11165-11170. [CrossRef]

16. Amato, M.E.; Ballistreri, F.P.; Pappalardo, A.; Sciotto, D.; Tomaselli, G.A.; Toscano, R.M. Synthesis and conformational aspects of 20- and 40-membered macrocyclic mono and dinuclear uranyl complexes incorporating salen and (R)-BINOL units. Tetrahedron 2007, 63, 9751-9757. [CrossRef]

17. Amato, M.E.; Ballistreri, F.P.; Gentile, S.; Pappalardo, A.; Tomaselli, G.A.; Toscano, R.M. Recognition of Achiral and Chiral

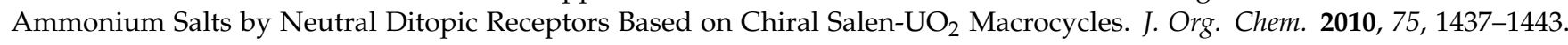
[CrossRef]

18. Patti, A.; Pedotti, S.; Ballistreri, F.P.; Trusso Sfrazzetto, G. Synthesis and Characterization of Some Chiral Metal-Salen Complexes Bearing a Ferrocenophane Substituent. Molecules 2009, 14, 4312-4325. [CrossRef] [PubMed]

19. Trusso Sfrazzetto, G.; Millesi, S.; Pappalardo, A.; Toscano, R.M.; Ballistreri, F.P.; Tomaselli, G.A.; Gulino, A. Olefin epoxidation by a (salen)Mn(III) catalyst covalently grafted on glass beads. Catal. Sci. Technol. 2015, 5, 673-679. [CrossRef]

20. Ballistreri, F.P.; Toscano, R.M.; Amato, M.E.; Pappalardo, A.; Gangemi, C.M.A.; Spidalieri, S.; Puglisi, R.; Trusso Sfrazzetto, G. A New Mn-Salen Micellar Nanoreactor for Enantioselective Epoxidation of Alkenes in Water. Catalysts 2018, 8, 129. [CrossRef]

21. Zammataro, A.; Gangemi, C.M.A.; Pappalardo, A.; Toscano, R.M.; Puglisi, R.; Nicotra, G.; Fragalà, M.E.; Tuccitto, N.; Trusso Sfrazzetto, G. Covalently functionalized carbon nanoparticles with a chiral Mn-Salen: A new nanocatalyst for enantioselective epoxidation of alkenes. Chem. Commun. 2019, 55, 5255-5258. [CrossRef]

22. Ballistreri, F.P.; Gangemi, M.A.; Pappalardo, A.; Tomaselli, G.A.; Toscano, R.M.; Trusso Sfrazzetto, G. (Salen)Mn(III) Catalyzed Asymmetric Epoxidation Reactions by Hydrogen Peroxide in Water: A Green Protocol. Int. J. Mol. Sci. 2016, 17, 1112. [CrossRef]

23. Legnani, L.; Iannazzo, D.; Pistone, A.; Celesti, C.; Giofrè, S.; Romeo, R.; Di Pietro, A.; Visalli, G.; Fresta, M.; Bottino, P.; et al. Functionalized polyhedral oligosilsesquioxane (POSS) based composites for bone tissue engineering: Synthesis, computational and biological studies. RSC Adv. 2020, 10, 11325-11334. [CrossRef]

24. Legnani, L.; Puglisi, R.; Pappalardo, A.; Chiacchio, M.A.; Trusso Sfrazzetto, G. Supramolecular recognition of phosphocholine by an enzyme-like cavitand receptor. Chem. Commun. 2020, 56, 539-542.

25. Chiacchio, M.A.; Legnani, L.; Caramella, P.; Tejero, T.; Merino, P. Revealing carbocations in highly asynchronous concerted reactions: The ene-type reaction between dithiocarboxylic acids and alkenes. Tetrahedron 2018, 74, 5627-5634. [CrossRef] 
26. Chiacchio, M.A.; Legnani, L.; Caramella, P.; Tejero, T.; Merino, P. Pivotal Neighboring-Group Participation in Substitution versus Elimination Reactions-Computational Evidence for Ion Pairs in the Thionation of Alcohols with Lawesson's Reagent. Eur. J. Org. Chem. 2017, 14, 1952-1960. [CrossRef]

27. Frisch, M.J.; Trucks, G.W.; Schlegel, H.B.; Scuseria, G.E.; Robb, M.A.; Cheeseman, J.R.; Scalmani, G.; Barone, V.; Petersson, G.A.; Nakatsuji, H.; et al. Gaussian 16, Revision C.01; Gaussian, Inc.: Wallingford, CT, USA, 2016.

28. Becke, A.D. Density-functional thermochemistry. III. The role of exact exchange. J. Chem. Phys. 1993, 98, 5648-5652. [CrossRef]

29. Lee, C.; Yang, W.; Parr, R.G. Development of the Colle-Salvetti correlation-energy formula into a functional of the electron density. Phys. Rev. B 1988, 37, 785-789. [CrossRef] [PubMed]

30. Cances, E.; Mennucci, B.; Tomasi, J. A new integral equation formalism for the polarizable continuum model: Theoretical background and applications to isotropic and anisotropic dielectrics. J. Chem. Phys. 1997, 107, 3032-3042. [CrossRef]

31. Cossi, M.; Barone, V.; Cammi, R.; Tomasi, J. Ab initio study of solvated molecules: A new implementation of the polarizable continuum model. Chem. Phys. Lett. 1996, 255, 327-335. [CrossRef]

32. Barone, V.; Cossi, M.; Tomasi, J. Geometry optimization of molecular structures in solution by the polarizable continuum model. J. Comput. Chem. 1998, 19, 404-417. [CrossRef]

33. Sasaki, H.; Irie, R.; Hamada, T.; Suzuki, K.; Katsuki, T. Rational design of Mn-salen catalyst. 2: Highly enantioselective epoxidation of conjugated cis-olefins. Tetrahedron 1994, 50, 11827-11838. [CrossRef]

34. Irie, R.; Noda, K.; Ito, Y.; Matsumoto, N.; Katsuki, T. Catalytic asymmetric epoxidation of unfunctionalized olefins using chiral (salen) manganese(III) complexes. Tetrahedron Asymmetry 1991, 2, 481-494. [CrossRef] 